\title{
Implications of observed inconsistencies in carbonate chemistry measurements for ocean acidification studies
}

\author{
C. J. M. Hoppe, G. Langer, S. D. Rokitta, D. A. Wolf-Gladrow, and B. Rost \\ Alfred Wegener Institute for Polar and Marine Research, 27570 Bremerhaven, Germany \\ Correspondence to: C. J. M. Hoppe (clara.hoppe@awi.de)
}

Received: 23 January 2012 - Published in Biogeosciences Discuss.: 14 February 2012

Revised: 9 May 2012 - Accepted: 3 June 2012 - Published: 3 July 2012

\begin{abstract}
The growing field of ocean acidification research is concerned with the investigation of organism responses to increasing $p \mathrm{CO}_{2}$ values. One important approach in this context is culture work using seawater with adjusted $\mathrm{CO}_{2}$ levels. As aqueous $p \mathrm{CO}_{2}$ is difficult to measure directly in smallscale experiments, it is generally calculated from two other measured parameters of the carbonate system (often $A_{T}, C_{T}$ or $\mathrm{pH}$ ). Unfortunately, the overall uncertainties of measured and subsequently calculated values are often unknown. Especially under high $p \mathrm{CO}_{2}$, this can become a severe problem with respect to the interpretation of physiological and ecological data. In the few datasets from ocean acidification research where all three of these parameters were measured, $p \mathrm{CO}_{2}$ values calculated from $A_{T}$ and $C_{T}$ are typically about $30 \%$ lower (i.e. $\sim 300 \mu \mathrm{atm}$ at a target $p \mathrm{CO}_{2}$ of $1000 \mu \mathrm{atm}$ ) than those calculated from $A_{T}$ and $\mathrm{pH}$ or $C_{T}$ and $\mathrm{pH}$. This study presents and discusses these discrepancies as well as likely consequences for the ocean acidification community. Until this problem is solved, one has to consider that calculated parameters of the carbonate system (e.g. $p \mathrm{CO}_{2}$, calcite saturation state) may not be comparable between studies, and that this may have important implications for the interpretation of $\mathrm{CO}_{2}$ perturbation experiments.
\end{abstract}

\section{Introduction}

Since the beginning of the Industrial Revolution, $\mathrm{CO}_{2}$ emissions from the burning of fossil fuels and changes in land use have increased atmospheric $\mathrm{CO}_{2}$ levels from preindustrial values of $280 \mathrm{ppm}$ to currently $390 \mathrm{ppm}$ (www.esrl.noaa.gov/ gmd/ccgg/trends; data by Tans and Keeling, NOAA/ESRL). Values are expected to rise to $750 \mathrm{ppm}$ (IPCC scenario IS92a,
IPCC, 2007) or even beyond 1000 ppm by the end of this century (Raupach et al., 2007). In addition to its contribution to the broadly discussed greenhouse effect, about $25 \%$ of anthropogenic $\mathrm{CO}_{2}$ has been taken up by the ocean (Canadell et al., 2007), causing a shift of the carbonate chemistry towards higher $\mathrm{CO}_{2}$ concentrations and lower $\mathrm{pH}$ (Broecker et al., 1971). This process, commonly referred to as ocean acidification (OA), is already occurring and is expected to intensify in the future (Kleypas et al., 1999; Wolf-Gladrow et al., 1999; Caldeira and Wickett, 2003). Ocean acidification will affect marine biota in many different ways (for reviews see Fabry et al., 2008; Rost et al., 2008).

To shed light on potential responses of organisms and ecosystems, numerous national and international research projects have been initiated (see Doney et al., 2009). An essential part of OA research is based on $\mathrm{CO}_{2}$ perturbation experiments, which represent the primary tool for studying responses of key species and marine communities to acidification of seawater. Marine biologists working in this field have to deal with several problems associated with this type of experiment: being especially interested in high $p \mathrm{CO}_{2}$ scenarios, seawater carbonate chemistry needs to be adjusted and kept quasi-constant over the duration of an experiment (in many cases, the carbonate chemistry is not at all controlled after initial adjustment). Also, the correct determination of at least two parameters is necessary to obtain a valid description of the whole carbonate system and hence correctly interpret organism responses.

Aqueous $p \mathrm{CO}_{2}$ is difficult to measure in small-scale experiments, and also $\mathrm{pH}$ has been under debate due to intricacies concerning $\mathrm{pH}$ scales and measurement protocols (Dickson, 2010; Liu et al. 2011). Total alkalinity $\left(A_{T}\right)$ and dissolved inorganic carbon $\left(C_{T}\right)$ are usually favoured as 
input parameters for carbonate chemistry calculations, because sample preservation and measurements are relatively straightforward. This combination of parameters had also been thought to lead to the most accurate calculations of $\mathrm{CO}_{2}$ concentrations and carbonate saturation states (Riebesell et al., 2010). Still, there is no agreement of which two parameters are to be measured, and, as a consequence, carbonate system calculations in different studies are often based on different input parameters. As will be shown here, this may severely impair comparability of different datasets.

Even though detailed literature on measurement protocols has been published (Dickson et al., 2007; Gattuso et al., 2010), potential pitfalls and problems with uncertainty estimations remain and, as certified reference materials (CRMs) are only available for current surface ocean conditions, the quality of carbonate chemistry measurements at high $p \mathrm{CO}_{2}$ levels is often unknown. Uncertainties of estimated $p \mathrm{CO}_{2}$ values are generally considered to be smaller than $10 \%$ (c.f. Gattuso et al., 2010; Hydes et al., 2010). An examination of the few over-determined datasets assessed in OA laboratories (including data from our own laboratory; reported in the Supplement) reveals up to $30 \%$ discrepancies between estimated $p \mathrm{CO}_{2}$ levels derived from different input pairs $\left(A_{T} \&\right.$ $\left.C_{T} ; A_{T} \& \mathrm{pH} ; C_{T} \& \mathrm{pH}\right)$. This potentially widespread phenomenon has major implications for the comparability and quantitative validity of studies in the OA community. In view of the growing body of OA literature and its impact on public opinion and policy makers (Raven et al., 2005), the identification, quantification and prevention of common errors has to be an issue of high priority.

This publication is based on an earlier manuscript entitled "On $\mathrm{CO}_{2}$ perturbation experiments: Over-determination of carbonate chemistry reveals inconsistencies" (Hoppe et al. 2010).

\section{Results}

We present here a comparison of over-determined carbonate chemistry datasets found in the literature together with our own datasets. Only one dataset with more than two parameters of the carbonate system measured in OAlaboratories was found in the list of "EPOCA relevant publications" archived in the PANGEA ${ }^{\circledR}$ database (Nisumaa et al., 2010; http://www.epoca-project.eu/index.php/data.html): Schneider and Erez, (2006); another study was excluded from this analysis because of conflicting values between database and manuscript. In addition, the data from IglesiasRodriguez et al. (2008), Thomsen et al. (2010) and our own laboratory (Hoppe et al. 2010) are shown. For all datasets, values reported for relevant parameters (e.g. salinity, temperature, $\mathrm{pH}$ scale, etc.) and the dissociation constants of carbonic acid of Mehrbach et al. (1973; as refit by Dickson and Millero, 1987) were used to calculate $p \mathrm{CO}_{2}$ values at $15^{\circ} \mathrm{C}$ using the program $\mathrm{CO}_{2}$ sys (Pierrot et al., 2006). As infor-

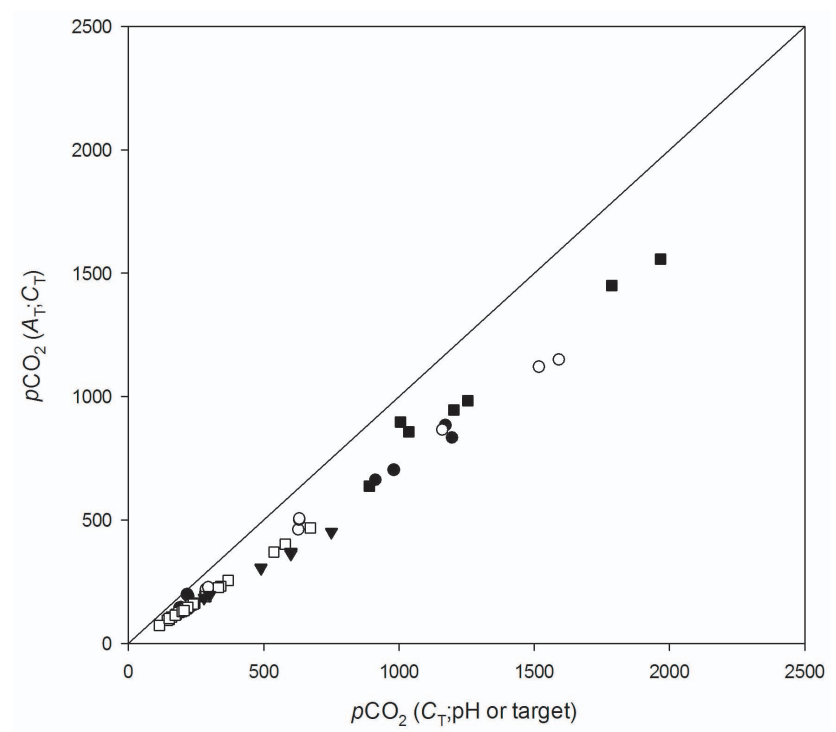

Fig. 1. Calculated $p \mathrm{CO}_{2}\left(A_{T} ; C_{T}\right)$ versus calculated $p \mathrm{CO}_{2}\left(C_{T}\right.$; $\mathrm{pH})$ in $\mu$ atm from this study (closed circles, natural seawater; open circles, artificial seawater), Schneider and Erez, 2006 (open squares), Thomsen et al., 2010 (closed squares) and IglesiasRodríguez et al., 2008 (closed triangles; here $p \mathrm{CO}_{2}$ (target) instead of $p \mathrm{CO}_{2}\left(C_{T} ; \mathrm{pH}\right)$ is given). $p \mathrm{CO}_{2}$ values were calculated for the respective salinity, nutrients and carbonate chemistry parameters at $15^{\circ} \mathrm{C}$ for all datasets.

mation on nutrient concentrations was lacking in the datasets used, values were based on appropriate literature data (see Supplement for details).

These calculations revealed discrepancies in the $p \mathrm{CO}_{2}$ calculated from different input pairs, which increased systematically with increasing $p \mathrm{CO}_{2}$ (Fig. 1). The $p \mathrm{CO}_{2}$ calculated from $C_{T}$ and $A_{T}$ was $\sim 30 \%$ lower than the $p \mathrm{CO}_{2}$ calculated from either $C_{T}$ and $\mathrm{pH}$ or from $A_{T}$ and $\mathrm{pH}$, the latter pairs yielding comparable results $( \pm 5 \%)$. The carbonate system of Iglesias-Rodriguez et al. (2008; as shown in the PANGEA ${ }^{\circledR}$ database) was not strictly over-determined. However, if one assumes equilibration of the aerated seawater with the gas mixtures used (280-750 ppm), the deviation of the $p \mathrm{CO}_{2}$ values (calculated from $A_{T}$ and $C_{T}$ ) from the target $p \mathrm{CO}_{2}$ reveals a similar relationship to that observed in the other datasets (Fig. 1). Even though outgassing in $C_{T}$ samples cannot be completely excluded as a potential source of the discrepancies in this particular study, the consistent pattern among studies argues strongly against this explanation.

With respect to our own dataset, further information is available. Discrepancies of $\sim 30 \%$ were observed irrespective of whether $C_{T}$ or $A_{T}$ was manipulated, and in both natural and artificial seawaters (NSW and ASW, respectively; Supplement, Table 2). 


\section{Discussion}

Underestimation of $p \mathrm{CO}_{2}$ calculated from measured values of $A_{T}$ and $C_{T}$ has been described in a number of studies from the marine chemistry community, in which direct measurements over a range of $p \mathrm{CO}_{2}$ levels (approx. 200-1800 $\mu$ atm) were compared to calculations from $A_{T}$ and $C_{T}$ (Lee et al., 1996, 2000; Wanninkhof et al., 1999; Luecker et al., 2000; Millero et al., 2002). The magnitude of these deviations is, however, much smaller than found in our study (5-10\%; cf. Fig. 4 in Luecker et al., 2000). The latter datasets and those from the OA community differ in the magnitude of the discrepancies $(\sim 5-10 \%$ and $\sim 30 \%$, respectively). Thus, the phenomenon observed in our study seems to be different from the one documented by marine chemists.

Currently, we do not have an explanation for the discrepancies described here, although a few simple explanations, such as the uncertainties of dissociation constants or uncertainties attributed to $A_{T}, C_{T}$ or $\mathrm{pH}$ measurements, can be ruled out: Systematic errors in measured $A_{T}\left(5 \mu \mathrm{mol} \mathrm{kg}{ }^{-1}\right.$; based on repeated CRM measurements, our own data), $C_{T}$ ( $7 \mu \mathrm{mol} \mathrm{kg}{ }^{-1}$; based on repeated CRM measurements, our own data), $\mathrm{pH}$ (0.02; Liu et al., 2011) and in equilibrium constants $\left(0.01\right.$ in $\mathrm{pK}_{1}^{*}, 0.02$ in $\mathrm{pK}_{2}^{*}$; Dickson, 2010) would be much too small to explain the large discrepancies in calculated $p \mathrm{CO}_{2}$.

The contribution of dissolved organic matter (DOM) to alkalinity has recently gained a lot of attention (Kim and Lee, 2009; Koeve et al., 2010). However, changes in $A_{T}$ due to DOM cannot cause the discrepancies described here, since the phenomenon was also observed in an experiment in which artificial seawater without any organic compounds or organisms was used (Supplement, Table 2). Furthermore, experiments with nutrient-enriched North Sea seawater (our data), probably DOM-rich water from Kiel Bight (Thomsen et al., 2010) and from the oligotrophic Red Sea (Schneider and Erez, 2006) show essentially identical discrepancies (Fig. 1). Nonetheless, DOM contributions can become a significant source of error in high biomass cultures (Kim and Lee, 2009).

It remains puzzling that these discrepancies are observed in experiments involving both $A_{T}$ and $C_{T}$ adjustments, different seawater compositions, as well as in several datasets produced with different equipment and procedures (e.g. coulometric, colourimetric and manometric $C_{T}$ measurements). The fact that several independent studies carried out within the framework of ocean acidification research show similar discrepancies between calculated $p \mathrm{CO}_{2}$ values (Fig. 1) suggests a systematic, as opposed to a random, deviation that will hinder a realistic judgement of the quality of datasets.

Regardless of the reasons for its occurrence, this phenomenon will have consequences for ocean acidification research. Firstly, published $p \mathrm{CO}_{2}$ values may not be comparable if different input parameters were measured and used to calculate $p \mathrm{CO}_{2}$. Secondly, if calculated $p \mathrm{CO}_{2}$ values are underestimated by up to $30 \%$, an organism's respective sensitivity to acidification might be severely overestimated. This is especially important at $p \mathrm{CO}_{2}$ levels $\geq 750 \mu \mathrm{atm}$, which are typically applied for the year 2100 scenario and therefore crucial for all $\mathrm{CO}_{2}$ perturbation experiments. As an example, one might refer to the responses of four Emiliania huxleyi strains to different $p \mathrm{CO}_{2}$ levels reported by Langer et al. (2009). For strain RCC1256, the authors report strongly decreasing calcification rates above $p \mathrm{CO}_{2}$ values of $600 \mu$ atm ( $p \mathrm{CO}_{2}$ values were derived from $A_{T}$ and $C_{T}$ measurements). As the study of Langer et al. (2009) was conducted in the same laboratory as this one, the presence of the described discrepancies can be assumed. If the $p \mathrm{CO}_{2}$ values from Langer et al. (2009) are indeed $\sim 30 \%$ lower than the ones calculated from $A_{T}$ and $\mathrm{pH}$ (or $C_{T}$ and $\mathrm{pH}$ ), our study could suggest that calcification increases until a $p \mathrm{CO}_{2}$ of $750 \mu \mathrm{atm}$ and only declines at values above $800 \mu \mathrm{atm}$. Predictions for this strain for the often proposed 2100 scenario of $750 \mu$ atm would thus differ substantially. The discrepancies in calculated $p \mathrm{CO}_{2}$ values described here might also explain the differing results reported by Langer et al. (2009) and Hoppe et al. (2011) with respect to the sensitivity of this strain. Thirdly, depending on the input pair chosen, the calculated carbonate ion concentration and hence the calcite and aragonite saturation states might differ significantly. In this study, discrepancies in saturation states were found to be in the range of $15-30 \%$.

Care must therefore be taken when comparing studies that use different pairs of input parameters or when reporting threshold levels of $p \mathrm{CO}_{2}$ harmful to an organism. To improve comparability between future studies, it may be useful to agree on a certain pair of input parameters as long as the described discrepancies remain. We suggest, for the time being, that the OA community should use $A_{T}$ and $\mathrm{pH}$ as input parameters when calculating the carbonate chemistry and, whenever possible, measure and report additional parameters. This suggestion does, however, not mean that the resulting $p \mathrm{CO}_{2}$ values are "correct". Although choosing a particular pair of parameters provides a pragmatic approach to dealing with such discrepancies, it is unsatisfying and if the choice results in inaccurate calculations of $p \mathrm{CO}_{2}$ and $\left[\mathrm{CO}_{3}^{2-}\right]$ - may lead to inappropriate interpretations of organism responses. Currently, we have neither sufficient understanding of the uncertainties of carbonate chemistry measurements, nor a clear demonstration that it is possible to get thermodynamically consistent data of $A_{T}, C_{T}, \mathrm{pH}$ and $p \mathrm{CO}_{2}$ for seawater samples with $p \mathrm{CO}_{2}>600 \mu \mathrm{atm}$ (A. Dickson personal communication, 2011). Further investigations on source and occurrence of this phenomenon are necessary. Certified reference material with high $p \mathrm{CO}_{2}$, as well as calculation programs including the propagation of errors, could improve estimations of uncertainties in carbonate chemistry measurements and therewith calculations of $p \mathrm{CO}_{2}$ values. It should become common practise to provide and defend 
estimates of uncertainty. A large-scale inter-comparison of the quality of carbonate chemistry measurements between different laboratories (from the OA but also from the marine chemistry community) would help revealing whether the phenomenon described here is indeed widespread.

\section{Supplementary material related to this article is available online at: http://www.biogeosciences.net/9/ 2401/2012/bg-9-2401-2012-supplement.zip.}

Acknowledgements. This work was supported by the European Research Council under the European Community's Seventh Framework Programme (FP7/2007-2013)/ ERC grant agreement No. 205150 and 2010-NEWLOG ADG-267931 HE). It also contributes to EPOCA under the grant agreement No. 211284, to MedSeA under grant agreement No. 265103 and to the BIOACID program (FKZ 03F0608). We thank A. Dickson who helped to improve this manuscript substantially. Also, we would like to thank T. Tyrrell for his helpful review as well as comments on an earlier version of this manuscript.

Edited by: J.-P. Gattuso

\section{References}

Broecker, W. S., Li, Y. H., and Peng, T. H.: Carbon Dioxide - Man's Unseen Artifact, in: Impingement of Man on the Ocean, edited by: Hood, D. W., Wiley, New York, USA, 287-324, 1971.

Caldeira, K. and Wickett, M. E.: Oceanography: Anthropogenic carbon and ocean pH, Nature, 425, p. 365, 2003.

Canadell, J. G., C. Le Quere, C., Raupach, M. R., Field, C. B., Buitenhuis, E. T., Ciais, P., Conway, T. J., Gillett, N. P., Houghton, R. A. and Marland, G.: Contributions to accelerating atmospheric $\mathrm{CO}(2)$ growth from economic activity, carbon intensity, and efficiency of natural sinks, P. Natl. Acad. Sci. USA, 104, 18866-18870, 2007.

Dickson, A. G.: The carbon dioxide system in sea water: equilibrium chemistry and measurements, in: Guide for Best Practices in Ocean Acidification Research and Data Reporting, edited by: Riebesell U., Fabry V. J., Hansson L. and Gattuso J.-P., Office for Official Publications of the European Union, Luxembourg, 2010.

Dickson, A. G. and Millero F. J.: A comparison of the equilibrium constants for the dissociation of carbonic acid in seawater media, Deep-Sea Res., 34, 1733-1743, 1987.

Dickson, A. G., Sabine, C. L., and Christian, J. R. (Eds.): Guide to best practices for ocean $\mathrm{CO}_{2}$ measurements, PICES Special Publication, 3, Sidney, Canada, 2007.

Doney, S. C., Balch, W. M. Fabry, V. J., and Feely, R. A.: Ocean Acidification: A Critical Emerging Problem for the Ocean Sciences, Oceanography, 22, 16-25, 2009.

Fabry, V. J., Seibel, B. A., Feely, R. A., and Orr, J. C.: Impacts of ocean acidification on marine fauna and ecosystem processes, ICES J. Mar. Sci., 65, 414-432, 2008.
Gattuso, J.-P., Lee, K., Rost, B., and Schulz, K.: Approaches and tools to manipulate the carbonate chemistry, in: Guide for Best Practices in Ocean Acidification Research and Data Reporting, edited by: Riebesell, U., Fabry, V. J., Hansson, L., and Gattuso, J.-P., Office for Official Publications of the European Union, Luxembourg, 2010.

Hoppe, C. J. M., Langer, G., Rokitta, S. D., Wolf-Gladrow, D. A., and Rost, B.: On $\mathrm{CO}_{2}$ pertubation experiments: overdetermination of carbonate chemistry reveals inconsistencies, Biogeosciences Discuss., 7, 1707-1726, doi:10.5194/bgd-71707-2010, 2010.

Hoppe, C. J. M., Langer, G., and Rost, B.: Emiliania huxleyi shows identical responses to elevated $p \mathrm{CO}_{2}$ in TA and DIC manipulations, J. Exp. Mar. Biol. Ecol., 406, 54-62, 2011.

Hydes, D. J., Loucaides, S., and Tyrrell, T.: Report on a desk study to identify likely sources of error in the measurements of carbonate system parameters and related calculations, Supplement to DEFRA contract ME4133 "DEFRApH monitoring project. National Oceanography Centre, Southampton Research and Consultancy Report, No.x, 54 pp., 2010.

Iglesias-Rodriguez, M. D., Buitenhuis, E. T., Raven, J. A., Schofield, O. M., Poulton, A. J., Gibbs, S., Halloran, P. R., and Baar, H. J. W. d.: Phytoplankton Calcification in a High- $\mathrm{CO}_{2}$ world, Science, 322, 336-340, 2008.

IPPC: Climate Change 2007: Synthesis Report, Contribution of Working Groups I, II and III to the Fourth Assessment Report of the Intergovernmental Panel on Climate Change (Core Writing Team Pachauri, R. K. and Reisinger, A. (Eds.)) IPCC, Geneva, Switzerland, 2007.

Kim, H.-C. and Lee, K.: Significant contribution of dissolved organic matter to seawater alkalinity, Geophys. Res. Lett., 36, L20603, 5 pp., 2009.

Kleypas, J. A., Buddemeier, R. W., Archer, D. E., Gattuso, J.-P., Langdon, C., and Opdyke, B. N.: Geochemical consequences of increased atmospheric carbon dioxide on coral reefs, Science, 284, 118-120, 1999.

Koeve, W., Kim, H.-C., Lee, K., and Oschlies, A.: Potential impact of DOC accumulation on $f \mathrm{CO}_{2}$ and carbonate ion computations in ocean acidification experiments, Biogeosciences Discuss., 8, 3797-3827, doi:10.5194/bgd-8-3797-2011, 2011.

Langer, G., Nehrke, G., Probert, I., Ly, J., and Ziveri, P.: Strainspecific responses of Emiliania huxleyi to changing seawater carbonate chemistry, Biogeosciences, 6, 2637-2646, 2009, http://www.biogeosciences.net/6/2637/2009/.

Lee, K., Millero, F. J., and Campbell, D. M.: The reliability of the thermodynamic constants for the dissociation of carbonic acid in seawater, Mar. Chem., 55, 233-245, 1996.

Lee, K., Millero, F. J., Byrne, R. H., Feely, R. A., and Wanninkhof, R.: The recommended dissociation constants for carbonic acid in sea water, Geophys. Res. Lett., 27, 229-232, 2000.

Liu, X., Patsavas, M. C., and Byrne, R. H.: Purification and Characterization of meta-Cresol Purple for Spectrophotometric Seawater pH Measurements, Environ. Sci. Technol., 45, 4862-4868, 2011.

Lueker, T. J., Dickson, A. G., and Keeling, C. D.: Ocean $\mathrm{pCO}_{2}$ calculated from dissolved inorganic carbon, alkalinity, and equations for $\mathrm{K}_{1}$ and $\mathrm{K}_{2}$ : validation based on laboratory measurements of $\mathrm{CO}_{2}$ in gas and seawater at equilibrium, Mar. Chem., 70, 105-119, 2000. 
Mackey, K. R., Rivlin, T., Grossman, A. R., Post, A. F., and Paytan, A.: Picophytoplankton responses to changing nutrient and light regimes during a bloom, Mar. Biol., 158, 1531-1546, 2009.

Mehrbach, C., Culberson, C. H., Hawley, J. E., and Pytkowicz, R. M.: Measurement of the apparent dissociation constants of carbonic acid in seawater at atmospheric pressure, Limnol. Oceanogr., 18, 897-907, 1973.

Millero, F. J., Pierrot, D., Lee, K., Wanninkhof, R., Feely, R., Sabine, C. L., Key, R. M., and Takahashi, T.: Dissociation constants for carbonic acid determined from field measurements, Deep-Sea Res., 49, 1705-1723, 2002.

Pierrot, D. E., Lewis, E., and Wallace, D. W. R.: MS Exel Program Developed for $\mathrm{CO}_{2}$ System Calculations, ORNL/CDIAC105aCarbon Dioxide Information Analysis Centre, Oak Ridge National Laboratory, US Department of Energy, 2006.

Raupach, M. R., Marland, G., Ciais, P., Le Quéré, C., Canadell, J. G., Klepper, G., and Field, C. B.: Global and regional drivers of accelerating $\mathrm{CO}_{2}$ emissions, Proc. Natl. Acad. Sci. USA, 104, 10288-10293, 2007.

Raven, J. A., Caldeira, K., Elderfield, H., Hoegh-Guldberg, O., Liss, P., Riebesell, U., Shepherd, J., Turley, C., and Watson, A.: Ocean acidification due to increasing atmospheric carbon dioxide, The Royal Society, Cardiff, UK, 2005.

Riebesell U., Fabry V. J., Hansson L., and Gattuso J.-P. (Eds.): Guide for Best Practices in Ocean Acidification Research and Data Reporting, Office for Official Publications of the European Union, Luxembourg, 2010.
Rost, B., Zondervan, I., and Wolf-Gladrow, D. A.: Sensitivity of phytoplankton to future changes in ocean carbonate chemistry: current knowledge, contradictions and research directions, Mar. Ecol. Prog. Ser., 373, 227-237, 2008.

Schneider, K. and Erez, J.: The effect of carbonate chemistry on calcification and photosynthesis in the hermatypic coral Acropora eurystoma, Limnol. Oceanogr., 51, 1284-1293, 2006.

Thomsen, J., Gutowska, M. A., Saphörster, J., Heinemann, A., Trübenbach, K., Fietzke, J., Hiebenthal, C., Eisenhauer, A., Körtzinger, A., Wahl, M., and Melzner, F.: Calcifying invertebrates succeed in a naturally $\mathrm{CO}_{2}$ enriched coastal habitat but are threatened by high levels of future acidification, Biogeosciences Discuss., 7, 5119-5156, doi:10.5194/bgd-7-5119-2010, 2010.

Wanninkhof, R., Lewis, E., Feely, R. A., and Millero, F. J.: The optimal carbonate dissociation constants for determining surface water $\mathrm{pCO}_{2}$ from alkalinity and total inorganic carbon, Mar. Chem., 65, 291-301, 1999.

Wolf-Gladrow, D. A., Riebesell, U., Burkhardt, S., and Bijma, J.: Direct effects of $\mathrm{CO}_{2}$ on growth and isotopic composition of marine plankton, Tellus, 51, 461-476, 1999. 